\title{
UM ESTUDO A RESPEITO DE PITÁGORAS E DO PITAGORISMO
}

\author{
Marcos Paes Torrecilha ${ }^{1}$ \\ Arnaldo Borba ${ }^{2}$ \\ CAp-UERJ
}

\section{RESUMO:}

Apresentamos uma leitura do pitagorismo que nos interessa de modo particular para o ensino da física. Referências históricas importantes a respeito da primazia da matemática na linguagem científica são abordadas. A cosmologia pitagórica também tem um destaque, por sua característica principal de considerar a Terra como um planeta, deslocada do centro do universo, em órbita em torno de um fogo central.

Palavras-Chave: física - matemática - filosofia

\section{RESUMEN:}

Presentamos una lectura del pitagorismo que nos interesa de modo particular para la enseñanza de la física. Se abordan referencias históricas importantes a respecto de la primacía de las matemáticas en el lenguaje científico. Del mismo modo tiene relieve la cosmología pitagórica por la principal característica de considerar la Tierra como un planeta, dislocada del centro del universo, orbitando un fuego central.

Palabras-CLAVe: física - matemáticas - filosofía

\section{I - INTRODUÇÃO E OBJETIVOS}

Como filosofia, a doutrina inaugurada por Pitágoras pode ser resumida na concepção: os números são o princípio da realidade. Um elemento significativo é a duração da escola e a influência do pensamento pitagórico na posteridade. De Pitágoras até Arquitas de Tarento, a duração da escola é de aproximadamente 150 anos. Do início do pitagorismo até hoje, são mais de dois milênios. Mas, além do conhecido teorema, o que mais pode ser incorporado à educação dos jovens para a construção de um verda- deiro pensamento de caráter lógicomatemático, tão importante para os dias que correm? Procuramos encontrar algumas respostas nas linhas seguintes.

\section{II - MetOdOLOGIA}

Seguindo os contornos de uma pesquisa histórica, fundada numa preocupação nitidamente educacional, procurou-se construir um quadro geral de informações a respeito da criação e do desenvolvimento de conceitos relativos à ciência e tecnologia, basea- 
e-Mosaicos - Revista Multidisciplinar de Ensino, Pesquisa, Extensão e Cultura do Instituto de Aplicação Fernando Rodrigues da Silveira (CAp-UERJ) ANO 1 - V. 1 - N. 1 - JUNHO 2012 - ISSN: 2316-9303

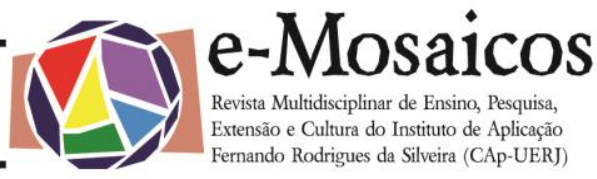

dos no nascimento da filosofia, com foco em Pitágoras e no pitagorismo. Foram utilizadas fontes de reconhecido valor, devidamente apontadas ao longo deste trabalho. $\mathrm{O}$ eixo interpretativo das informações coletadas esteve sempre voltado para a explicitação das cargas teóricas e na explicitação dos pressupostos presentes na construção de novos conceitos.

\section{III - ASPECTOS DA VIDA DE PITÁgoras}

Pitágoras estabeleceu-se em Crotona, depois de viagens que duraram cerca de 30 anos, devendo, portanto, à época, beirar os 50 anos de idade. Estudou com os sábios fenícios na Síria; no Egito, por cerca de 20 anos conviveu com os sacerdotes dos templos existentes nas margens do rio Nilo; foi levado para a Babilônia, como prisioneiro, após uma invasão persa ao Egito.

Seus problemas não acabaram em Crotona. Questões políticas o levaram a uma nova expulsão. A realidade comprovada pelos historiadores é que, depois da expulsão de Crotona, se organizaram várias comunidades pitagóricas no mundo helênico e, sobretudo, na Magna Grécia. Tais comunidades tiveram longa vida e aportaram notáveis desenvolvimentos à obra do mestre fundador. As duas mais importantes foram: a escola de Filolau - que viveu em meados do século V, tendo surgido na Magna Grécia e sido transferida a Tebas, e a de Arquitas (início do século IV) - que floresceu em Tarento e dominou a cidade também politicamente. Esta última exerceu grande influência em Platão e na Academia. De Filolau nos chegaram os principais fragmentos, base principal para reconstituir a doutrina de $\mathrm{Pi}$ tágoras.

Pode-se caracterizar Pitágoras como um dos pensadores mais originais da história. É o iniciador da ciência matemática e da cosmologia filosófica, exposta de maneira mais organizada e acabada que seus predecessores. Naturalmente, a busca da ciência matemática vinha combinada com crenças religiosas, o que determinava uma preponderância dos aspectos morais, no sentido de sustentar uma concepção de vida, que deveria ser seguida por todos os membros da escola. A existência de um indivíduo, Pitágoras, o fundador da escola, é atestada, então, mais pelas fortes impressões exercidas no pensamento posterior do que por fontes contemporâneas isentas. Ele foi o primeiro grego a conceber a importância da alma, daí o exame de consciência diário, o pensar a respeito do crescimento espiritual, proporcionado por cada dia de estudo e de prática de um comportamento pessoal. A harmonia cósmica, uma vez descoberta e decifrada, nos seus elementos matemáticos, seria a diretriz do comportamento individual e também da forma de governo mais adequada às cidades.

\section{IV - MÚSICA, MATEMÁTICA E FÍSICA}

No pitagorismo, a matemática e a música estão ligadas. A música é instrumento de conhecimento e de elevação espiritual. As variações sonoras decorrem dos diferentes comprimentos da corda de um monocórdio. Daí a generalização: todas as coisas são números. De acordo com a conhecida obra de história da ciência (Ronan, 1987), temos uma visão dessa concepção pitagórica.

"(...) notaram haver uma relação matemática entre as notas da escala musical e os comprimentos de uma corda vibrante ou de uma coluna de ar em vibração (...) Uma coluna de ar ou uma corda de determinado comprimento daria uma nota; reduzido, então, à metade de seu comprimento, daria 
e-Mosaicos - Revista Multidisciplinar de Ensino, Pesquisa, Extensão e Cultura do Instituto de Aplicação Fernando Rodrigues da Silveira (CAp-UERJ) ANO 1 - V. 1 - N. 1 - JUNHO 2012 - ISSN: 2316-9303

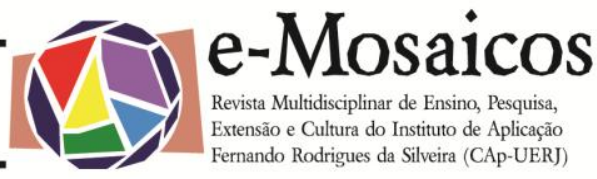

uma nota uma oitava acima. Uma relação de comprimento de 2 para 3 daria o intervalo musical conhecido como quinta, e a relação de 3 para 4, uma quarta. Assim, se alguém usa uma corda vibrante com 12 unidades de comprimento e a reduz a 8 unidades, ela soará uma quinta acima da nota original; se a reduzirmos a 6 unidades, ela soará a oitava. Assim, como a oitava e a quinta eram consideradas sons harmônicos, Pitágoras disse que os números 12,8 e 6 estavam em <<progressão harmônica>> e considerou isso tão importante que estendeu a ideia à geometria, tendo em razão disso declarado que o cubo estava em harmonia geométrica porque tinha seis faces, oito ângulos e doze arestas."

Com respeito ao famoso teorema, o trecho a seguir é esclarecedor.

"A segunda observação referia-se aos triângulos retângulos. No Egito, Pitágoras teria aprendido a regra de 3,4 e 5, referente aos comprimentos dos lados, mas uma pesquisa moderna mostrou que foi na Babilônia que encontrou o que chamamos de relação de Pitágoras. Os babilônios, de fato, tinham chegado à conclusão que os números podiam ser $3,4,5$ ou $6,8,10$ ou qualquer outra combinação onde o quadrado do maior dos lados fosse igual à soma dos quadrados dos dois outros. Este era um passo adiante deveras decisivo, e os pitagóricos iriam fazer ótimo uso dele." (Ronan, 1987).

Mas o teorema, ou seja, a regra segundo a qual a soma dos quadrados dos catetos é igual ao quadrado da hipotenusa, também está na raiz da crise do pitagorismo e da sua concepção de que tudo poderia ser reduzido aos números. De fato, como aparece em Ronan:

"A descoberta dos números irracionais, pelos pitagóricos, está ligada ao triângulo re- tângulo cujos dois lados menores são iguais a 1 , o que leva a que a hipotenusa tenha valor igual a raiz de 2 . Como a escola pitagórica considerava que toda realidade é produzida por unidades numéricas organizadas em certa ordem e quantidade, a descoberta de um número que não podia ser representado por tais unidades trouxe uma crise filosófica. Esse fato inseria uma irracionalidade, segundo o pensamento pitagórico, na própria essência do real." (Ronan, 1987)

Sobre a música e sua importância para os pitagóricos, citemos também algumas palavras de Nietzsche (Pré-Socráticos, 1985).

"O ponto de partida que permite afirmar que tudo o que é qualitativo é quantitativo encontra-se na acústica [física]. (...) A música, com efeito, é o melhor exemplo do que queriam dizer os pitagóricos. A música, como tal, só existe em nossos nervos e em nosso cérebro; fora de nós ou em si mesma (no sentido de Locke), compõe-se somente de relações numéricas quanto ao ritmo, se trata de sua quantidade, e quanto à tonalidade, se trata de sua qualidade, conforme se considere o elemento harmônico ou o elemento rítmico. No mesmo sentido, poderse-ia exprimir o ser do universo, do qual a música é, pelo menos em certo sentido, a imagem, exclusivamente com o auxílio de números" (Pré-Socráticos, 1985).

Os pitagóricos foram os primeiros a estudar geometria com base na aritmética. Vigorava a concepção de que era possível extrair as principais características das várias figuras geométricas, através do número de pontos (que, em cada caso, se supõe finito) que as compõe e, de outro modo, que fosse possível recorrer à forma das figuras para ilustrar as mais recônditas propriedades dos números. Por isso, se distinguiam 
os números em vários tipos, por exemplo, triangulares, quadrados, cúbicos, poligonais. Ao número triangular dez (ver figura abaixo) era atribuída uma importância especial,

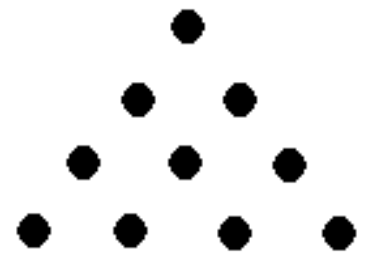

como soma dos quatro primeiros números naturais. Os ímpares se chamavam gnomones pela possibilidade de representá-los em forma de gnomon (ou seja, esquadra). Esta representação permite descobrir que cada número ímpar é a diferença de dois quadrados, por exemplo, $7=4 \times 4-3 \times 3$, ou ainda $11=6 \times 6-5 \times 5$, conforme mostra a figura.
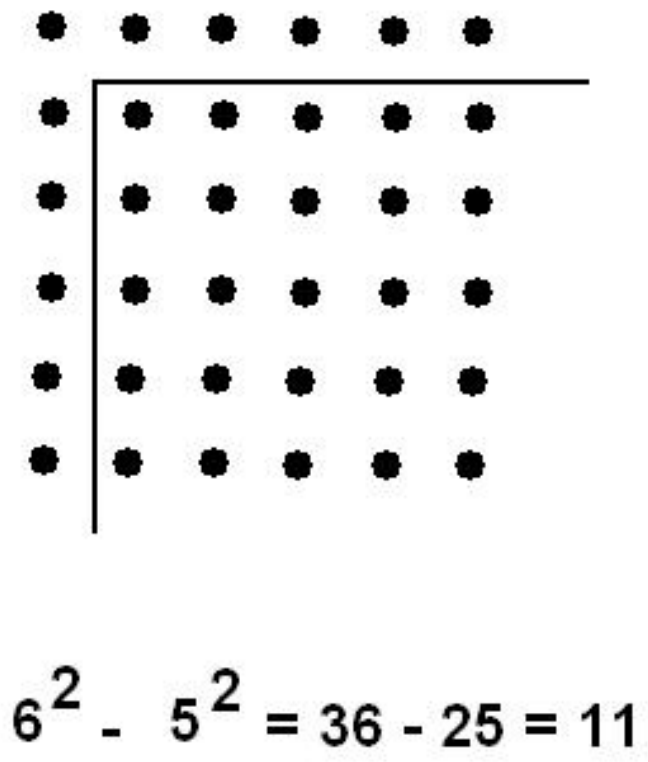

O Universo se desdobra em suas várias dimensões, de acordo com os primeiros números da sequência: a unidade é o ponto; o dois estabelece a linha; a superfície é gerada pelo três; o quatro engendra o volume. Nas palavras de Ludovico Geymonat:

"Com o termo <<números>> os pitagóricos se referiam só aos números inteiros, concebidos como a coleção de várias unidades. Não fizeram indagações particulares sobre a natureza destas unidades, limitando-se a representá-las com pontos, cada qual rodeado pelo espaço vazio." (Geymonat, 1998).

Era um problema essencial para os pitagóricos captarem a maneira em que, da coleção de várias unidades, se geravam todos os seres. As leis de formação dos números eram consideradas as leis de formação das coisas e se acreditava poder encontrar nelas a verdadeira razão explicativa do mundo físico e moral.

A mais importante destas leis estava constituída, segundo os pitagóricos, pela estrutura oposta dos números ímpares e dos pares. A antítese ímpar-par era considerada como princípio de uma série de outras nove oposições que partem o mundo em dois: limitado-ilimitado; um - muitos; direitaesquerda; masculino-feminino; luz-treva; bom-mau; imóvel-móvel; reto-curvo; quadrado-oval.

Algumas destas oposições tinham nitidamente um caráter físico (por exemplo, a de luz-treva; dela surgia a representação do cosmos como constituído por um fogo central, imerso em uma extensão ilimitada de névoa); outras, ao contrário, tinham um preciso caráter moral. Esta presença de múltiplos significados terminava por infundir aos números em geral e a alguns deles em particular um verdadeiro valor mágicosimbólico. Dessa maneira, o número 5 representava o matrimônio, ao ser a soma do 
e-Mosaicos - Revista Multidisciplinar de Ensino, Pesquisa, Extensão e Cultura do Instituto de Aplicação Fernando Rodrigues da Silveira (CAp-UERJ) ANO 1 - V. 1 - N. 1 - JUNHO 2012 - ISSN: 2316-9303

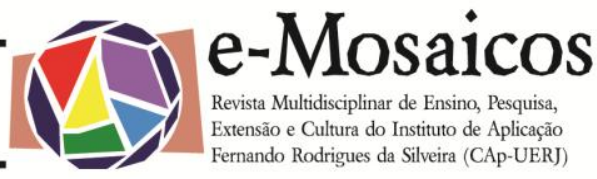

primeiro número ímpar, o 3, com o primeiro número par, o 2."

O número1 se considerava par-ímpar e servia em geral tanto aos números pares como ímpares; a unidade compartilha da natureza tanto do par como do ímpar, pois se adicionamos 1 ao par tornamo-lo ímpar e se adicionamos 1 ao ímpar tornamo-lo par. Os números 4 e 9 se tomavam como símbolos da justiça; o 7 da oportunidade.

Voltando-nos para o aspecto mais científico, novamente vale a pena citar Nietzsche, no mesmo texto já citado, para transitar da matemática para a física (PréSocráticos, 1985).

"(...) Trata-se de encontrar fórmulas matemáticas para as forças absolutamente impenetráveis. Nossa ciência é, nesse sentido, pitagórica. (...) A contribuição original dos pitagóricos é, pois, uma invenção extremamente importante: a significação do número e, portanto, a possibilidade de uma investigação exata em física. Nos outros sistemas de física, tratava-se sempre de elementos e de sua combinação. As qualidades nasciam por combinação ou por dissociação; agora, enfim, afirma-se que as qualidades residem na diversidade das proporções. Mas esse pressentimento estava ainda longe da aplicação exata. Contentouse, provisoriamente, com analogias fantasiosas."

\section{V - COSMOLOGIA PITAGÓRICA}

O traço mais notável da cosmologia pitagórica consistiu em haver deslocado a Terra do centro do universo e tê-la convertido em um mero planeta, em órbita em torno de um fogo central. Acreditavam não ver esse fogo central porque viveriam em um lado da Terra afastado deste. O mesmo sistema incluía, junto com o Sol, a Lua e os demais planetas conhecidos, uma antiTerra, invisível, pela mesma razão anterior. Não é o fato de o fogo central não ser identificado com o Sol o que mais impressiona na teoria cosmológica pitagórica. $\mathrm{O}$ fato mais importante é a atribuição de um movimento orbital para a Terra. A criação de uma anti-Terra só tem a razão de se completar o número dez, associado com a perfeição; de resto, isto resulta irrelevante. Também, é importante enfatizar, não se trata de uma antecipação da teoria heliocêntrica.

Uma descrição mais detalhada do sistema é: no centro está o fogo e a Terra se move na segunda órbita a partir deste centro; na primeira órbita gira a anti-Terra; em seguida temos a Lua, o Sol, que refletia a luz e o calor vindos do fogo central, os cinco planetas e por fim a esfera das estrelas fixas que limita o todo e é de fogo como o centro. Na Lua existiria vida e esta seria de maior duração e mais pura do que a vivida na Terra, de acordo com a tradição religiosa grega, que dizia aumentar o grau de pureza à medida em que se subia em direção à esfera das estrelas fixas. A Lua seria uma fronteira importante, entre o mundo sublunar e o supra-lunar. Uma maior necessidade para a existência da anti-Terra estava relacionada com a explicação dos eclipses da Lua, que os pitagóricos atribuíam à entrada desta na sombra da Terra. Pela freqüência destes eclipses, acreditava-se na existência da anti-Terra. A Lua ficava encoberta, por vezes pela sombra da Terra, por outras vezes pela sombra da anti-Terra.

De tudo isso podemos perceber que são três as razões para se postular a existência do fogo central, de uma Terra e de uma anti-Terra orbitando em torno a este fogo. Primeiro: o número de corpos em órbita deve atingir a perfeição do número dez; 
segundo: o fogo inspirava um temor religioso e a posição central justificava títulos como Trono de Zeus; terceiro: o sistema poderia ser justificado porque ajudava a explicar fenômenos naturais como os eclipses.

\section{VI - CONCLUSÕES}

Esta é apenas uma leitura do pitagorismo. Muito mais se poderia dizer a respeito dessa filosofia que, durante tantos séculos, influenciou todo o pensamento científico e filosófico. Do ponto de vista educacional, queremos contribuir para o enriquecimento cultural da juventude. Deliberadamente não tocamos no assunto do famoso teorema no corpo de discussão do presente trabalho. Cabe aqui, nestas conclusões, um comentário: o teorema tem um caráter prático e sabe-se que já era conhecido dos egípcios. Pitágoras o incorporou à ciência grega e, ao que tudo indica, generalizou a famosa tríade 3, 4, 5 para qualquer combinação de múltiplos ou submúltiplos destes três números. Continuaremos ensinando o teorema durante muitos e muitos anos, mas esperamos que os conteúdos principais da filosofia pitagórica sejam incorporados ao ensino cotidiano.

\section{VII - REFERÊNCIAS BIBLIOGRÁFICAS}

GEYMONAT, Ludovico. Historia de la filosofía y de la ciencia. Barcelona, Ed. Crítica, 1998.

PRÉ-SOCRÁTICOS. São Paulo, Abril Cultural, col. "Os Pensadores", 1975.

RONAN, Colin A. História Ilustrada da Ciência, v. 1: Das origens à Grécia, Rio de Janeiro, Jorge Zahar, 1987.

${ }^{1}$ marcostorrecilha@yahoo.com.br - Bacharel em Física pela Universidade Federal de São Carlos, Licenciado em Física pela Universidade do Esta- do do Rio de Janeiro e Mestre em Física, pela Universidade Federal do Rio de Janeiro. Atualmente é Professor Docente da Universidade do Estado do Rio de Janeiro / Instituto de Aplicação Fernando Rodrigues da Silveira - CAp-UERJ e da Rede Estadual de Educação do Estado do Rio de Janeiro.

2 arnaldoborba@bol.com.br - Licenciado e Bacharel em Física pela Faculdade de Humanidades Pedro II (1978) e Mestrado em Geofísica pelo Observatório Nacional (2001). Atua desde 1980 como professor no Ensino Médio na rede privada e estadual. Professor Assistente da Universidade do Estado do Rio de Janeiro desde 1987, atuando atualmente na Universidade do Estado do Rio de Janeiro / Instituto de Aplicação Fernando Rodrigues da Silveira - CAp-UERJ. 